\title{
Occurrence of theoretically correct responses during rotation of the Ames window ${ }^{1}$
}

\author{
C. H. GRAHAM ${ }^{2}$ AND B. J. GILLAM \\ COLUMBIA UNIVERSITY
}

It has been hypothesized (Graham, 1963) that reversals in the Ames window are the outcome of a resolution of ambiguous differential angular velocity cues by linear perspective cues. This theory was tested. A parallel projection of the window on an opal glass screen was used as the stimulus. Ss almost always reported two apparent reversals per rotation. The long vertical side of the figure was always apparently in front of the short vertical side. These results were interpreted to be in line with theoretical expectations.

Graham (1963) proposed that reversals in the apparent direction of motion (oscillations) of the rotating Ames (1951) trapezoidal window arise from (1) the ambiguity of motion parallax cues with respect to the direction of rotary nustion, and (2) the resolution of this ambiguity by means of the linear perspective of the figure that is seen in such a way that the short side always appears behind the frontal plane and the long side in front. This mode of viewing is consistent with apparent oscillation and not with rotation.

Day and Power (1965) attribute apparent reversals in motion of the window to the ambiguity of the expansion and contraction of the retinal image, and they deny the importance of linear perspective in determining the reversals. They found that ellipses and irregularly shaped forms (1963), which lack these precise cues, elicited as many apparent reversals as did the Ames window.

Graham's account calls for two apparent reversals per revolution of the window, an effect correlated with the fact that the long vertical side always appears closer to the $S$ than the short vertical side (Graham, 1963, $1965,1968)$. One reversal is reported in the zero degree position at the left of the frontal plane following a movement of the long side behind the frontal plane; that side is then reported to move in front of the frontal plane. A second reversal (back to the physical direction of motion) follows continued rotation of the long side through $180 \mathrm{deg}$ of rotation to the front of the frontal plane. This alternation continues throughout rotation.

Day and Power obtained on the average only about one reversal per rotation of their trapezoid, ellipses, and irregular figures and fewer for their rectangle. This observed reversal frequency of the trapezoid, about one half the one predicted for Graham's account, is consistent with Day and Power's view that reversal and continued rotation are equally probable effects at each point of change from expansion to contraction of the retinal image and vice versa. Reversals are apparently considered "spontaneous" effects by Day and Power.

In Day and Power's experiments Ss viewed figures subtending a horizontal visual angle of $10 \mathrm{deg}$, which is sufficiently large to provide effectively polar projection on the retina. As Hershberger (1967) points out, angular velocity cues are not identical for opposite directions of rotary motion in polar projection (see also MacRae \& Power, 1969); furthermore he showed that Ss can discriminate to a degree better than chance between opposite directions of motion in polar projection on the basis of angular velocity cues alone. At small visual angles the retinal image approaches a parallel projection of the viewed figure, and the difference in angular velocity cues for opposite directions of motion becomes infinitesimally small.

Zegers (1964), using a trapezoidal window of approximately the dimensions of Day and Power's, found that reversal frequency increases with decreasing visual angle to $5 \mathrm{deg}$, thus suggesting that the latter angle, possibly providing a less-than-threshold difference from parallel projection, is important in obtaining the optimum number of reversals. Further analysis of data of this sort may show retinal size to have a limiting effect on the presence or absence of a two-per-rotation rate of reversal.

In polar projection the stimulus variables that must be considered in analyzing the frequency of apparent reversals are complex. Both vertical and horizontal angular velocity cues to the direction of motion may exist in considerable strength under conditions of polar projection (Jansson \& Borjesson, 1969). These cues will conflict with those provided by the perspective of the window. Perhaps one may dominate at one time, the other at another time, and sometimes conditions may favor intermittently seen reversals. The low reversal frequency of the rectangle in Day and Power's experiments indicates that angular velocity cues for direction of motion were suprathreshold for this figure and almost certainly for their window also. For figures without linear perspective such as circles, ellipses, and irregular figures, angular velocity cues for direction of motion may be less discriminable. Freeman and Pasnak (1968) discuss some of the factors determining reversal rate in polar projection.

In parallel projection, on the other hand, the argument of Graham (1963) does hold that differential velocity cues are identical for opposite directions of motion. The present experiment was designed to test the hypothesis that reversals of the rotating trapezoidal window follow perspective indications when angular velocity cues are perfectly ambiguous or nearly so. The stimulus was a parallel projection of the figure on a screen, an arrangement that also eliminated interposition and brightness cues. The prediction was tested that two reversals per single rotation should occur when the window passes through the frontal plane.

\section{PROCEDURE:}

\section{EXPERIMENTS 1A, 1a, $1 \mathrm{~B}$}

For both experiments $S s$ viewed a silhouette of an Ames window on an opal glass screen. Different sizes of window were used in the two experiments but the proportions were the same. The windows were painted flat black with the "panes" cut out. The silhouette was a near-parallel projection of the figure in Experiment 1A and a parallel projection of the figure in Experiment 1B. For both experiments rotation was at the rate of 3 per min.

Experiment $1 \mathrm{~A}$, performed on nine men and one woman, used a window $8.45 \mathrm{~cm}$ in its horizontal dimension and with the center of rotation $5 \mathrm{~cm}$ from the long vertical side. It was interposed in the slightly diverging rays from a $S$ diopter lens placed $16.5 \mathrm{~cm}$ from a point source of light. (Slightly divergent rays were used to eliminate distortions due to spherical aberration that were observed in the projected silhouette when the lens was placed at $20 \mathrm{~cm}$ from the point source to give collimated rays.) The window was placed $38 \mathrm{~cm}$ in front of the lens, $48.5 \mathrm{~cm}$ behind the opal glass screen, and cast a 
shadow $11.7 \mathrm{~cm}$ in horizontal dimension on the screen. The silhouette was not measurably different for equal angles of rotary motion in opposite directions untik the window was beyond $\pm 30 \mathrm{deg}$ of the frontal plane. The silhouette was viewed at a distance of $2.6 \mathrm{~m}$. In these circumstances, the angular width of the window extended in the frontal-plane was $2.8 \mathrm{deg}$.

In Experiment la, observations simiar to those of $1 \mathrm{~A}$ were made by four Ss but with binocular regard.

Experiment 1B, performed on three men and seven women, used a smaller window, $4.52 \mathrm{~cm}$ in frontal plane extent. The small size and the fact that the window was placed very close to the screen effectively eliminated distortions in the projection when the lens was placed at its focal length $(20 \mathrm{~cm})$ from the point source, and a parallel projection of the rotating figure was obtained on the screen by placing it in the collimated beam $7 \mathrm{~cm}$ from the screen. The vertical sides of the figure were 2.8 and $3.9 \mathrm{~cm}$.

The $S$ viewed the silhouette from a distance of $90 \mathrm{~cm}$. Thus the visual angle frontal plane extent of the figure was essentially the same as the window of Experiment 1A. This visual extent in the frontal plane of the window was, in both experiments, $2.8 \mathrm{deg}$.

In Experiments $1 \mathrm{~A}, 1 \mathrm{a}$, and $1 \mathrm{~B}$, the $\mathrm{S}$ signaled perceived reversals in the direction of the motion of the window by pressing a button. These responses were recorded as follows: A cam was attached to the vertical rod on which the window was mounted and which formed the latter's axis of rotation. The cam was placed so that as the long side of the window reached a 0 deg position in the frontal plane a rotary switch was triggered so that it could close a circuit, normally open, through $24 \mathrm{deg}$ and then open it again at the end of the cam. If $S$ pressed the button to indicate a reversal during this 24-deg $(1.3 \mathrm{sec})$ period, the circuit was completed and activated a counter to move one digit. In this manner the frequency of afferent reversals occurring within $24 \mathrm{deg}$ of the $0 \mathrm{deg}$ position could be counted. A similar switch arrangement was placed in the $180-\mathrm{deg}$ position to count reversals occurring between $180 \mathrm{deg}$ and $204 \mathrm{deg}$ as the long side of the window passed over this region. If $S$ pressed his button so that a signal occurred anywhere outside these two regions of the rotation cycle, a third circuit was completed that could only be closed when the other two circuits were open; by the latter arrangement a third counter was moved one digit. Another rotary switch automatically activated a fourth counter as the cam moved over it, thus recording the total number of physical rotations.

Table $1 \mathrm{~A}$

Hits and Misses in Each Series of 10 Rotations for Each of 10 Ss. Absolute width of window, $8.45 \mathrm{~cm}$. Each $\mathrm{S}$ was tested in five complete series. Theoretical maximum hits in each series $=20$ (i.e., 2 per single rotation). Monocular observation. Average hits per rotation for nine Ss (S5 excluded) $=1.88$.

\begin{tabular}{|c|c|c|c|c|c|c|c|c|c|c|c|}
\hline \multirow{2}{*}{\multicolumn{2}{|c|}{$\begin{array}{c}\text { Consecutive } \\
\text { Series of } 10 \\
\text { Revolutions Each }\end{array}$}} & \multicolumn{10}{|c|}{ Subjects } \\
\hline & & \multirow{2}{*}{$\frac{1}{20}$} & \multirow{2}{*}{$\begin{array}{r}2 \\
20 \\
0\end{array}$} & \multirow{2}{*}{$\frac{3}{10}$} & \multirow{2}{*}{$\frac{4}{20}$} & \multirow{2}{*}{$\frac{5}{6}$} & \multirow{2}{*}{-6} & \multirow{2}{*}{$\begin{array}{r}7 \\
20 \\
0\end{array}$} & \multirow{2}{*}{$\frac{8}{18}$} & \multirow{2}{*}{$\frac{9}{18}$} & \multirow{2}{*}{$\begin{array}{r}10 \\
15 \\
5\end{array}$} \\
\hline 1. & $\begin{array}{l}\text { Hits } \\
\text { Misses }\end{array}$ & & & & & & & & & & \\
\hline 2. & $\begin{array}{l}\text { Hits } \\
\text { Misses }\end{array}$ & $\begin{array}{r}20 \\
0\end{array}$ & $\begin{array}{r}20 \\
0\end{array}$ & $\begin{array}{r}16 \\
4\end{array}$ & $\begin{array}{r}20 \\
0\end{array}$ & $\begin{array}{r}2 \\
17\end{array}$ & $\begin{array}{r}17 \\
3\end{array}$ & $\begin{array}{r}19 \\
1\end{array}$ & $\begin{array}{r}18 \\
2\end{array}$ & $\begin{array}{r}18 \\
2\end{array}$ & $\begin{array}{r}20 \\
0\end{array}$ \\
\hline 3. & $\begin{array}{l}\text { Hits } \\
\text { Misses }\end{array}$ & $\begin{array}{r}20 \\
0\end{array}$ & $\begin{array}{r}20 \\
0\end{array}$ & $\begin{array}{c}20 \\
0\end{array}$ & $\begin{array}{r}19 \\
1\end{array}$ & $\begin{array}{r}11 \\
9\end{array}$ & $\begin{array}{r}20 \\
0\end{array}$ & $\begin{array}{r}20 \\
0\end{array}$ & $\begin{array}{r}19 \\
1\end{array}$ & $\begin{array}{r}19 \\
1\end{array}$ & $\begin{array}{r}18 \\
2\end{array}$ \\
\hline 4. & $\begin{array}{l}\text { Hits } \\
\text { Misses }\end{array}$ & $\begin{array}{r}20 \\
0\end{array}$ & $\begin{array}{r}20 \\
0\end{array}$ & $\begin{array}{r}20 \\
0\end{array}$ & $\begin{array}{r}20 \\
0\end{array}$ & $\begin{array}{r}7 \\
13\end{array}$ & $\begin{array}{r}19 \\
1\end{array}$ & $\begin{array}{r}2 \theta \\
0\end{array}$ & $\begin{array}{r}18 \\
2\end{array}$ & $\begin{array}{r}18 \\
2\end{array}$ & $\begin{array}{r}20 \\
0\end{array}$ \\
\hline 5. & $\begin{array}{l}\text { Hits } \\
\text { Misses }\end{array}$ & $\begin{array}{r}20 \\
\theta\end{array}$ & $\begin{array}{r}20 \\
0\end{array}$ & $\begin{array}{r}20 \\
0\end{array}$ & $\begin{array}{r}20 \\
0\end{array}$ & $\begin{array}{r}4 \\
16\end{array}$ & $\begin{array}{r}20 \\
0\end{array}$ & $\begin{array}{r}20 \\
0\end{array}$ & $\begin{array}{r}20 \\
0\end{array}$ & $\begin{array}{r}19 \\
1\end{array}$ & $\begin{array}{r}20 \\
0\end{array}$ \\
\hline
\end{tabular}

1. All misses were just outside the region except for $S 5$ monoeular, who behaved erratically.

2. The dominant eye was used for monocular observations.

3. The regions counted as hits were $0.24 \mathrm{deg}$ and $180-204 \mathrm{deg}$.

The $\mathrm{S}$ was seated $90 \mathrm{~cm}$ from the screen with a patch (not in 1a) placed over one eye. The following instructions were then given by E: "I want you to watch the figure projected on the screen. How does the figure appear to move? Tell me what you see." $S$ then watched the window silhouette and described its movement until he reported: "back and forth," "to and fro," or some such equivalent phrase. E wrote down S's response.

Thereafter $\mathbf{E}$ gave further instructions: "Now I want you to observe the whole figure. As soon as you see it appear to reverse its direction of movement, press this button and do so at each reversal. Release the button as quickly as you can after each press." (Demonstrate)

$S$ was then given five blocks of 10 clockwise rotations per block with a rest between blocks while $E$ recorded the readings on the counters. (In Experiment 1B $S$ was given four blocks rather than five blocks.) No $S$ wno was tested had ever had previous experience with the Ames window.

\section{EXPERIMENTS 1A, Ia, AND 1B}

Table lA shows for each $S$ the frequency of presses per 10 rotations in each of the three angular categories (0-24 deg, 180-204 deg) and "other" (i.e., 25-179 deg, 204-359 deg). Presses that occurred in the 0-24 and 180-204 deg categories were termed "hits" and those that occurred in the 25-179 and 205-359 deg (i.e., "other") category were termed "misses."

All Ss saw, with few exceptions, two reversals per rotation, one within the region $0.24 \mathrm{deg}$ and one within the region 180-204 deg. For all Ss the few responses that did register in the "other" category narrowly missed being "hits" as judged by $E$ (The $S$ had only $1.3 \mathrm{sec}$ of time within which to make a "hit" resonse.)

Table 1a gives results for binocular observations for four Ss (Experiment 1a) under conditions comparable to Experiment 1A. In these circumstances, all responses (except one) were "hits" occurring at the appropriate extremes of the frontal plane, in the angular intervals 0-24 and 180-204 deg, and at the rate of two per single rotation.

As shown in Table 1B, the results on rate of apparent reversal seem to be in accord with those of Table $1 \mathrm{~A}$.

\section{PROCEDURE AND RESULTS OF EXPERIMENT 2}

Following Experiments 1A, 1a, and 1B on position of reversals, observations were made on apparent direction of movement shown by the short vertical side during physical rotation.

The $S$ was shown the stationary figure in a frontal plane position and instructed as

Table 1 a

As in Table $1 \mathrm{~A}$, but with binocular observation. Four Ss. One miss (by S2) in possible total of 400 hits.

\begin{tabular}{|c|c|c|c|c|c|}
\hline \multirow{2}{*}{\multicolumn{2}{|c|}{$\begin{array}{c}\text { Consecutive } \\
\text { Series of } 10 \\
\text { Revolutions Each }\end{array}$}} & \multicolumn{4}{|c|}{ Subjects } \\
\hline & & \multirow{2}{*}{$\frac{1}{20}$} & \multirow{2}{*}{$\frac{2}{20}$} & \multirow{2}{*}{$\frac{3}{20}$} & \multirow{2}{*}{$\frac{4}{20}$} \\
\hline 1. & Hits & & & & \\
\hline & Misses & 0 & 0 & 0 & 0 \\
\hline \multirow[t]{2}{*}{2.} & Hits & 20 & 20 & 20 & 20 \\
\hline & Misses & 0 & 0 & 0 & 0 \\
\hline \multirow[t]{2}{*}{3.} & Hits & 20 & 20 & 20 & 20 \\
\hline & Misses & 0 & 0 & 0 & 0 \\
\hline \multirow[t]{2}{*}{4.} & Hits & 20 & 20 & 20 & 20 \\
\hline & Misses & 0 & 0 & 0 & 0 \\
\hline \multirow[t]{2}{*}{5.} & Hits & 20 & 19 & 20 & 20 \\
\hline & $\mathbf{M}$ isses & 0 & 1 & 0 & 0 \\
\hline
\end{tabular}


Table 1B

As in Table IA, but with small absolute width of window, $4.52 \mathrm{~cm}$. Four blocks of 10 revolutions per $\mathrm{S}$. Average hits per rotation for $10 \mathrm{Ss}=1.93$.

\begin{tabular}{|c|c|c|c|c|c|c|c|c|c|c|c|}
\hline \multirow{2}{*}{\multicolumn{2}{|c|}{$\begin{array}{l}\text { Consecutive } \\
\text { Blocks of } 10 \\
\text { Revolutions Fach }\end{array}$}} & \multicolumn{10}{|c|}{ Subjects } \\
\hline & & \multirow{2}{*}{$\frac{1}{20}$} & \multirow{2}{*}{$\frac{2}{17}$} & \multirow{2}{*}{$\frac{3}{18}$} & \multirow{2}{*}{$\frac{4}{20}$} & \multirow{2}{*}{$\frac{5}{20}$} & \multirow{2}{*}{$\frac{6}{20}$} & \multirow{2}{*}{$\frac{7}{17}$} & \multirow{2}{*}{$\frac{8}{19}$} & \multirow{2}{*}{$\frac{9}{17}$} & \multirow{2}{*}{$\frac{10}{20}$} \\
\hline 1. & $\begin{array}{l}\text { Hits } \\
\text { Misses }\end{array}$ & & & & & & & & & & \\
\hline 2. & $\begin{array}{l}\text { Hits } \\
\text { Misses }\end{array}$ & $\begin{array}{r}20 \\
0\end{array}$ & $\begin{array}{r}18 \\
2\end{array}$ & $\begin{array}{r}20 \\
0\end{array}$ & $\begin{array}{r}20 \\
0\end{array}$ & $\begin{array}{r}19 \\
1\end{array}$ & $\begin{array}{r}20 \\
0\end{array}$ & $\begin{array}{r}19 \\
0\end{array}$ & $\begin{array}{r}20 \\
0\end{array}$ & $\begin{array}{r}20 \\
0\end{array}$ & $\begin{array}{r}20 \\
0\end{array}$ \\
\hline 3. & $\begin{array}{l}\text { Hits } \\
\text { Misses }\end{array}$ & $\begin{array}{r}19 \\
1\end{array}$ & $\begin{array}{r}20 \\
0\end{array}$ & $\begin{array}{r}19 \\
1\end{array}$ & $\begin{array}{r}19 \\
1\end{array}$ & $\begin{array}{r}19 \\
1\end{array}$ & $\begin{array}{r}20 \\
0\end{array}$ & $\begin{array}{r}20 \\
0\end{array}$ & $\begin{array}{r}20 \\
0\end{array}$ & $\begin{array}{r}17 \\
3\end{array}$ & $\begin{array}{r}20 \\
0\end{array}$ \\
\hline 4. & $\begin{array}{l}\text { Hits } \\
\text { Misses }\end{array}$ & $\begin{array}{r}20 \\
0 \\
\end{array}$ & $\begin{array}{r}19 \\
1\end{array}$ & $\begin{array}{r}20 \\
0\end{array}$ & $\begin{array}{r}19 \\
1\end{array}$ & $\begin{array}{r}19 \\
1\end{array}$ & $\begin{array}{r}20 \\
0\end{array}$ & $\begin{array}{r}20 \\
0\end{array}$ & $\begin{array}{r}18 \\
2\end{array}$ & $\begin{array}{r}20 \\
0\end{array}$ & $\begin{array}{r}20 \\
0\end{array}$ \\
\hline
\end{tabular}

Hits-Button pressed within regions $0.24 \mathrm{deg}$ and $180.204 \mathrm{deg}$

Misses-Button pressed elsewhere

All Ss pressed the button twice per revolution. The misses were always just outside designated hit zones.

follows: "You can see that one side of the projected figure is shorter than the other. (Demonstrate) I want you to concentrate on this short side. Tell me whether, when the figure moves, the short side appears to move toward you or away from you during the various to and fro stages of oscillation." Observations were made only for clockwise rotations of the window. In connection with the statement concerning "stages of oscillation" E discussed "quadrants in a circle of rotation" by drawing a diagram.

All Ss reported on the initial apparent direction of motion of the short side starting from some stationary position in one of the quadrants (fore or aft of the frontal plane). Under the circumstances of clockwise rotation, the window demonstrated the following characteristics for movement in the first quarter revolution:

\section{Starting Quadrant Direction of Motion}

\begin{tabular}{ll} 
I & Toward S \\
II & Away from S \\
III. & Toward S \\
IV & Away from S \\
\hline
\end{tabular}

E noted the starting position of the windown on a diagram (Fig. 1), indicated $S$ 's response to the window, and thereafter designated his behavior in each quadrant during two complete revolutions. During all of the stages of physical rotation, the $S$

Fig. 1. The apparent direction of movement in the various quadrants shown by the short vertical side during physical rotation. Apparent movement away from the S labeled "recede," toward the S, "advance." The short side always appears in Quadrants I and II; the long side, in Quadrants III and IV. S facing figure from bottom of page. made judgments of the sort given the in the initial stage: The short side appeared as moving toward the $S$ in Quadrant $I$ and away from the $S$ in Quadrant II regardless of its true quadrant position. In a word, the short side always apeared behind the frontal plane in the position dictated by perspective; the long side always appeared near at hand in Quadrants III and IV.

\section{DISCUSSION}

The results of these experiments confirm certain interpretations concerning controlling variables in the apparent motion of the Ames window (Graham, 1963). Ambiguous motion parallax cues are combined with linear perspective cues to provide apparently oscillatory motion of the window in a manner that has been discussed (Graham, 1963, 1965, 1968).

The account predicts that, under appropriate circumstances, the reversals in the apparent direction of the window's motion occur when the vertical edges of the window are in the frontal plane, that is, when the window is perpendicular to the S's line of sight to the center of rotation. This prediction means that two apparent reversals of the window should appear in each complete rotation. (The sign of the apparent change in direction would depend on whether the reference object is the short or long vertical side, and also on the direction, counterclockwise or clockwise, of physical rotation.)

The theoretical predictions as to the movement characteristics so specified

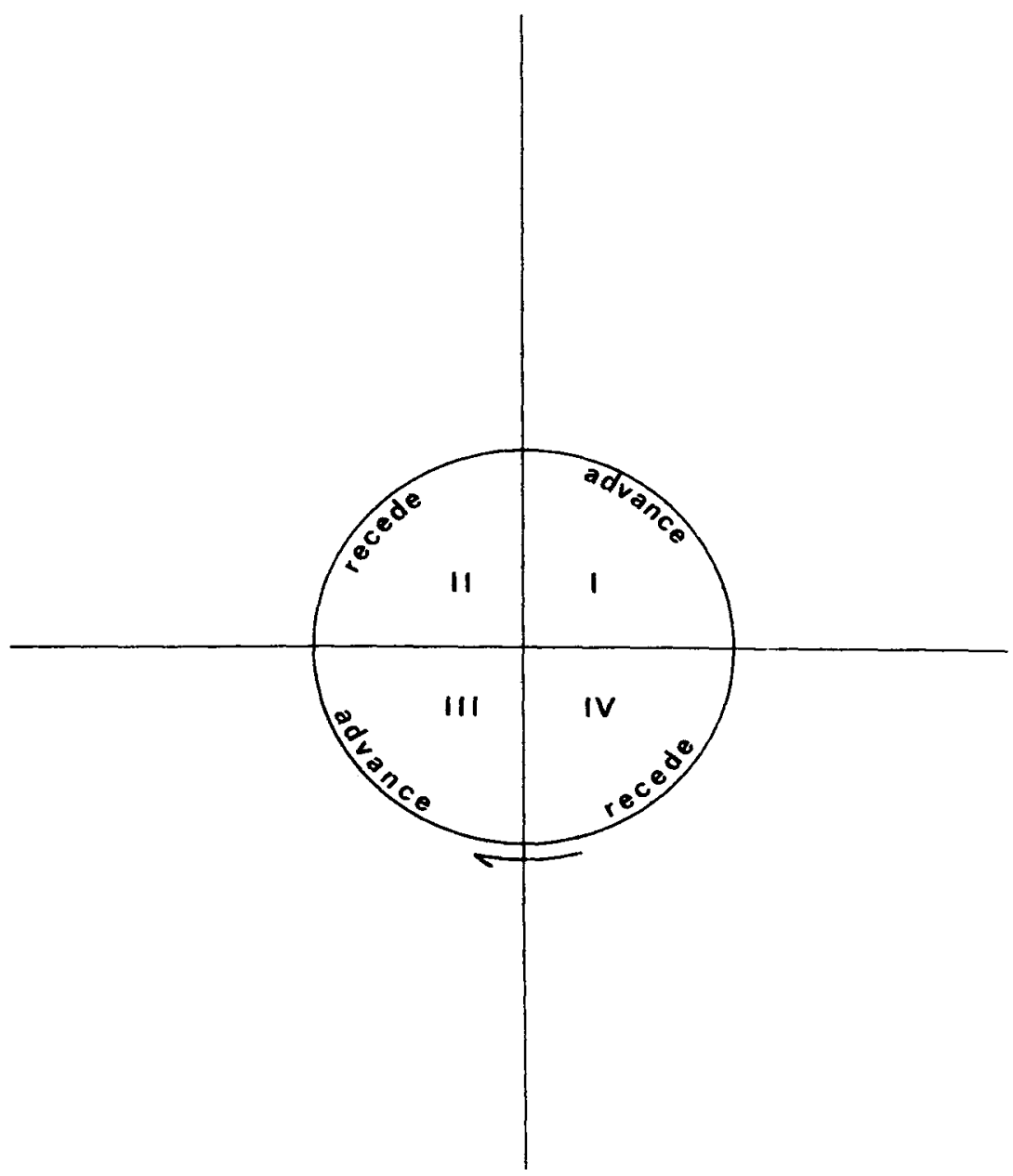


means that the apparent motion of the window (moving at a constant physical rate of rotation) should be perfectly regular. However, a number of factors may interfere with the regularity of the movement. Some of these may be the following: I1) effects of inappropriate instructions, (2) possible visual pathologies or optical aberrations, and (3) certain conditions of observation. For example, in the latter category is included nonparallelism of light rays in which $S$ views the window (Hershberger, 1967). If the window exceeds a certain angular width in the frontal plane the regularity and frequency of apparent reversals may be influenced in disharmony with predictions that hold for appropriate conditions.

Day and Power (1965) presented data that they seem to interpret as indicating the "spontaneous" nature of reversals. The results of the present experiment are not in accord with this belief. Rather an overwhelmingly high percentage of apparent reversals are in line with Graham's (1963) account. Further, the small percentage of "misses" noted in Tables 1A, $1 \mathrm{a}$, and 1B could (in E's opinion) be "hits," if a slightly more inclusive temporal or spatial criterion were applied to the latter category. In any case, it is worth emphasizing that many of the Ss show $100 \%$ of "hits," most strikingly in the binocular observations (Table 1a).

Day and Power (1965) seem to believe that the "spontaneous" nature of reversals preclude a dependence on cue resolution by linear perspective. The diagram of Fig. 1 shows the findings (Experiment 2) on apparent direction of movement of the short side during physical clockwise rotation of the window. The direction of motion of the short side (and necessarily the long side) was always in agreement with perspective principles. The short side was always seen (during the two test rotations of the window) as in Quadrants II and I; the long side was always necessarily seen in the reverse Quadrants, IV and III. Thus the data of window position and direction of initial movement (as well as later ovement) demonstrate the overall importance of linear perspective cues.

The context of the present experiments predict that (1) reversals occur when the vertical sides are physically in the frontal plane, (2) reversals occur at a two-per-cycle rate, and (3) the longer vertical side always appears closer than the shorter vertical side. The results were found to be in accord with these predictions (Tables 1A, 1a, 1B, and Fig. 1). They confirm the interpretation of the oscillatory movement (Graham, 1963) as arising from (1) the ambiguity of motion parallax cues with respect to the direction of rotary motion and (2) the resolution of this ambiguity by means of linear perspective cues

It is of considerable importance in view of these findings to emphasize details of experiments that do not show a regular two-per-cycle rate of reversal. Certainly the factors listed in the third paragraph of the Discussion are out of accord with certain desirable conditions of theoretical test.

\section{REFERENCES}

AMES, A. Visual perception and the rotating trapezoidal window. Psychological Monographs, 1951, 65 (7, Whole No. 324).

DAY, R. H., \& POWER, R. P. Frequency of apparent reversal of rotary motion in depth: An investigation and general theory. Psychological Review, 1965, 72, 117-127.

FREEMAN, R. B., Jr., \& PASNAK, R. Perspective determinants of the rotating trapezoidal illusion. Journal of Experimental Psychology, 1968, 76, 94-101.

GRAHAM, C. H. On some aspects of real and apparent visual movement. Journal of the Optical Society of America, 1963, 53, 1015-1025.

GRAHAM, C. H. Perception of movement. In C. H. Graham (Ed.), Vision and visual perception. New York: Wiley, 1965, Pp. 575-588.

GRAHAM, C. H. Depth and movement. American Psychologist, 1968, 23, 18-26.

HERSHBERGER, W. A. Comment on "Apparent reversal (oscillation) of rotary motion in depth." Psychological Review, 1967, 74, 235-238.

JANSSON, G., \& BORJESSON, E. Perceived direction of rotary motion. Perception \& Psychophysics, 1969, 6, 19-26.

MacRAE, K. D., \& POWER, R. P. Critical comment on one aspect of Graham's "On some aspects of real and apparent visual movement." Journal of the Optical Society of America, 1969, 59, 1002.

ZEGERS, R. T. The reversal lllusion or the ames trapezoid. Transactions of the New York Academy of Science, 1964, 26, 377-400.

\section{NOTES}

1. This work was supported by PHS Research Grant No. R01 EY 00391-02 from the National Eye Institute, by the Institutional Scientific Research Pool of Columbia University, and by Contract N00014-67-A-0009 between Columbia University and the Office of Naval Research. This paper, dated December 12,1969, is Technical Report No. 8 of the latter contract.

2. Address: 355 Schermerhorn Hall, Columbia University, New York, New York 10027

(Accepted for publication December 12, 1969.) 